\title{
Um protocolo de "nested-PCR" para deteç̧ão do vírus da anemia das galinhas ${ }^{1}$
}

\author{
Simone Simionatto ${ }^{2}$, Carlos André da Veiga Lima-Rosa ${ }^{3}$, Lauricio Librelotto Rubin ${ }^{2}$ e \\ Cláudio Wageck Canal ${ }^{2 *}$
}

\begin{abstract}
Simionatto S., Lima-Rosa C.A.V., Rubin L.L. \& Canal C.W. 2005. [A nested-PCR protocol for detection of the chicken anemia virus.] Um protocolo de "nested-PCR" para deteç̧ão do virus da anemia das galinhas. Pesquisa Veterinária Brasileira 25(2):106-110. Laboratório de Virologia, Faculdade de Veterinária, Universidade Federal do Rio Grande do Sul, Av. Bento Gonçalves 9090, Porto Alegre, RS 91540-000, Brazil. E-mail: claudio.canal@ufrgs.br

This paper reports a nested polymerase chain reaction (nested-PCR) protocol for detection of chicken anemia virus (CAV), the causal agent of infectious chicken anemia. For DNA extraction from clinical samples, a method based on guanidine thiocyanate was found more sensitive and practical than other extraction protocols tested. The pair of primers used in the initial PCR targeted a $664 \mathrm{bp}$ fragment on the VP1 gene. The primers for the internal PCR targeted a fragment of $520 \mathrm{bp}$. The specificity of the primers was evaluated on samples of CAV controlled flocks. Thirty different viruses and bacteria isolated from chickens did not give rise to any amplification product in the assay. The sensitivity of the nested-PCR was determined on serial dilutions of a CAV vaccine. The nested-PCR was more sensitive than a one step PCR and was able to detect at least $0.16 \mathrm{TCID}_{50}$ of the vaccine strain. In addition, the protocol employed here detected viral DNA from tissues, sera and litter from flocks with or without clinical signs of disease. It is concluded that the nested-PCR protocol described here is more sensitive, faster and less cumbersome than virus isolation in cell culture as a diagnostic technique for detection of CAV.
\end{abstract}

INDEX TERMS: Chicken anemia virus, CAV, molecular diagnosis, nested-PCR.

RESUMO.- Este trabalho descreve o estabelecimento de um pro!tocolo de "nested-PCR" para a deteç̧ão do vírus da anemia das galinhas ( $\mathrm{CAV}$, chicken anemia virus), agente causador da anemia infecciosa das galinhas. Para a extração de DNA a partir de amostras clínicas um método baseado no uso de tiocianato de guanidina mostrou-se mais sensível e prático, do que os demais avaliados. Para a PCR inicial foi selecionado um par de primers que amplifica uma região de 664 pares de bases $(\mathrm{pb})$ do gene VP1. Para a "nested-PCR" propriamente dita, foi selecionado um segundo par que amplifica uma região interna de $520 \mathrm{pb}$. A especificidade dos primers foi avaliada utilizando amostras de

\footnotetext{
${ }^{1}$ Recebido em 1 de dezembro de 2004.

Aceito para publicação em 27 de dezembro de 2004.

${ }^{2}$ Laboratório de Virologia, Departamento de Patologia Clínica Veterinária, Faculdade de Veterinária, Universidade Federal do Rio Grande do Sul (UFRGS), Av. Bento Gonçalves 9090, Porto Alegre, RS 91540-000. *Autor para correspondência. E-mail: claudio.canal@ufrgs.br

${ }^{3}$ Departamento de Biologia Molecular e Biotecnologia, UFRGS, Porto Alegre, RS.
}

lotes controlados para CAV. Outras trinta amostras vírus e bactérias, causadoras de doenças em aves, não geraram produto de amplificação. A sensibilidade do teste foi determinada a partir de diluições seriadas de uma amostra vacinal de CAV. A "nestedPCR" mostrou ser mais sensível do que a PCR e foi capaz de detectar pelo menos $0,16 \mathrm{TCID}_{50 \%}$ da cepa vacinal. Além disso, detectou DNA viral em tecidos, soro e cama aviária de lotes com e sem sinais clínicos. Conclui-se que, como técnica para a detecção do CAV, o protocolo de "nested-PCR" aqui descrito, é mais sensível, rápido e menos trabalhoso do que o isolamento viral em cultivo celular.

TERMOS DE INDEXAÇÃO: Vírus da anemia das galinhas, CAV, virologia, diagnóstico molecular, "nested-PCR".

\section{INTRODUÇÃO}

$\mathrm{O}$ vírus da anemia das galinhas $(\mathrm{CAV})$ pertence à família Circoviridae (Murphy 1996) gênero Gyrovirus (Pringle 1999). Este vírus foi isolado pela primeira vez no Japão em 1979 (Yuasa et al. 1979). Desde então, sua presença tem sido descrita em criações comerciais em quase todo o mundo (Schat 2003). 0 genoma do 
CAV é composto de DNA circular de fita simples com aproximadamente $2,3 \mathrm{~kb}$, possuindo três regiões codificadoras sobrepostas para a VP1 (51,6 kDa), VP2 (24,0 kDa) e VP3 (13,6 kDa) (Noteborn et al. 1991).

A transmissão do CAV se dá horizontalmente, de aves infectadas para aves suscetíveis (Yuasa et al. 1980) e verticalmente, de ovos provenientes de aves infectadas tanto soronegativas (Chettle et al. 1989) quanto na presença de altos níveis de anticorpos neutralizantes (Brentano et al. 2005). Por afetar células do sistema imune, particularmente hemocitoblastos da medula óssea e precursores de linfócitos T no timo, a imunodepressão decorrente favorece o surgimento de infecções secundárias oportunistas e falhas vacinais (Adair 2000).

Galinhas em todas as idades são suscetíveis à infecção, porém os sinais clínicos manifestam-se quando esta acontece nos primeiros dias de vida. A infecção subclínica é a forma mais freqüiente da doença, sendo responsável pelo aumento do índice de conversão alimentar e diminuição do peso médio, causando prejuízos ao produtor (McNulty et al. 1991).

O diagnóstico de infecções pelo CAV é realizado através do isolamento viral, detecção de anticorpos ou identificação de segmentos do genoma (Schat 2003). Além de o isolamento viral apresentar baixa sensibilidade (Cardona et al. 2000), diferenças genéticas interferem na replicação do vírus (Renshaw et al. 1996) o que impossibilita o isolamento de algumas cepas (Islam et al. 2002). Já os testes sorológicos indicam uma exposição prévia ao vírus e não uma infecção presente (Schat 2003).

A reação em cadeia da polimerase (PCR) é uma técnica molecular que permite a deteç̧ão do DNA do CAV de forma rápida e econômica, tendo sido descritos protocolos de PCR que detectam o DNA viral a partir de tecidos e soro de aves, assim como de cultivos celulares e (Tham \& Stanislawek 1992, Todd et al. 1992, Imai et al. 1998, Cardona et al. 2000, Yilmaz et al. 2001). Alguns pesquisadores, entretanto, somente obtiveram sucesso à amplificação do DNA do CAV quando as aves apresentavam sinais clínicos (Davidson et al. 2004). O presente trabalho descreve um protocolo de "nested-PCR" de alta sensibilidade, capaz de detectar o DNA viral em tecidos, soro e cama aviária, de lotes com e sem sinais clínicos da infecção.

\section{MATERIAL E MÉTODOS}

\section{Infeç̧ão Experimental}

Pintos de ovos SPF (Granja Rezende, MG) com seis dias de vida foram divididos em dois grupos de 12 animais. $\mathrm{O}$ grupo controle negativo (Grupo A) recebeu $0,2 \mathrm{~mL}$ de solução salina tamponada com fosfato (PBS, $0,15 \mathrm{M} \mathrm{NaCl}, 0,01 \mathrm{M} \mathrm{Na}_{2} \mathrm{PO}_{4}, \mathrm{pH} \mathrm{7,2)} \mathrm{por} \mathrm{via}$ intramuscular. Neste mesmo dia, pintos em outro grupo (Grupo B) foram inoculados com $0,2 \mathrm{~mL}$ da vacina Nobilis CAV P4 (Intervet International, Holanda), partida 004/03, com $10^{2,3}$ doses infectantes para $50 \%$ dos cultivos celulares $\left(\mathrm{DICC}_{50 \%}\right.$ ), por via intramuscular.

\section{Amostras}

Os animais (inoculados e controles) foram sacrificados aos $0,2,4$, 14, 21 e 28 dias após a inoculação. Em cada coleta, 2 animais de cada grupo foram sacrificados, sendo coletadas amostras de timo, baço, fígado, medula óssea, bolsa de Fabrício e sangue/soro. A determinação do método de extração de DNA mais adequado foi, inicialmente, realizada com fragmentos de órgãos e tecidos dos animais inoculados.
A seguir, foram testados amostras de cama aviária, órgãos e soros de galinhas de diferentes lotes provenientes das empresas responsáveis por mais de $90 \%$ da produção de carne de frangos da Região Sul do Brasil. Soros de frangos de corte sem anticorpos para CAV e os soros de matrizes com anticorpos para CAV foram obtidos como descrito por Rubin et al. (2003) e Canal et al. (2004), respectivamente. Como controle negativo, foram utilizadas amostras provenientes de dois lotes de reprodutoras avós, negativos para a presença de anticorpos contra o CAV durante todo o seu ciclo de vida, como monitorado através de um kit de ELISA comercial (Kirkegaard and Perry Laboratories). No Quadro 1 estão discriminados o número e o tipo de amostras analisadas.

\section{Extração de DNA}

Quatro diferentes protocolos de extração de DNA foram testados: 1) extração com brometo de cetil trimetil amônia/cloreto de sódio (CTAB/NaCl) (Sambrook \& Russell 2001); 2) extração com fenol/ clorofórmio (Sambrook \& Russell 2001); 3) extração com dodecil sulfato de sódio /EDTA (Hirt 1967); e 4) extração com tiocianato de guanidina (adaptado de Rademaker \& Bruijn1997). Cada protocolo foi testado sobre $200 \mu \mathrm{L}$ de soro ou $20 \mathrm{mg}$ de órgãos (timo, fígado, baço, bolsa de Fabrício e medula óssea), coletados dos animais inoculados experimentalmente. Os tecidos foram macerados em $200 \mathrm{iL}$ de TE (1 mM EDTA, $10 \mathrm{mM}$ Tris-HCl pH 8,0) em tubo Eppendorf de 1,5 mL, com o auxílio de um palito de madeira. Das amostras de cama aviária, foram utilizados $200 \mu \mathrm{L}$ de uma solução contendo $0,5 \mathrm{~g}$ de cama ressuspendida em $5 \mathrm{~mL}$ de TE. Após a avaliação dos distintos protocolos de extração de DNA, optou-se pelo método baseado na extração com tiocianato de guanidina (Rademaker \& Bruijn 1997), adaptado como segue. Tecidos ou soro foram colocados em um tubo Eppendorf com 500 ì de solução GES (5 M de tiocianato de guanidina, $0,03 \mathrm{M}$ de Nlauroil sarcosine, $1 \mathrm{mM}$ EDTA), sendo o tubo agitado levemente e incubado à $4{ }^{\circ} \mathrm{C}$ por 5 minutos. A seguir, foram adicionados $250 \mathrm{iL}$ de acetato de amônia $7,5 \mathrm{M}$, sendo o tubo novamente agitado suavemente e incubado a $4^{\circ} \mathrm{C}$ por 5 minutos. Após, foram adicionados 500 ì de fenol clorofórmio/álcool isoamílico (25:24:1), submetendo o tubo a agitação vigorosa e centrifugação a $10.000 \times \mathrm{g}$ por 10 minutos. $\mathrm{O}$ DNA foi então precipitado com 380 ì de isopropanol e lavado com 500 ì de etanol $80 \%$. O sedimento foi ressuspenso em 100 ì de TE e estocado a $-20^{\circ} \mathrm{C}$ até ser utilizado na PCR.

\section{Primers}

Com a ajuda do programa Vector $\mathrm{NTI}^{\mathrm{TM}}$ Suite 8.0 (InforMax Inc. 2002), foram selecionados dois pares de primers a partir do alinhamento de todas as seqüências de DNA do CAV disponíveis no Genbank ${ }^{\circledR}$ no final do ano de 2002. Os primers CAV7 (5'TTT CGACATCGGAGGAGACAGG3') e CAV8 (5'CCTTTTCGCCACCGG TTCTGGT3'), correspondendo aos nucleotídeos 925 a 1589 do genoma da cepa Cux-1 (Genbank acesso número M81223), foram usados na PCR inicial, objetivando a amplificação de um segmento de 624 pares de bases; os primers CAV9 (5'CGTATAGTGTGAGGCTGCCG3') e CAV10 (5'GAGAGAAGACTCGCCACGG3') correspondendo aos nucleotídeos 978 a 1517 do genoma da mesma cepa, foram usados na "nested-PCR", objetivando a amplificação de um produto de 520 pare de bases.

\section{Reações de amplificação}

A PCR inicial foi realizada em um volume final de $25 \mathrm{~mL}$ contendo aproximadamente $100 \mathrm{ng}$ de DNA molde, $10 \mathrm{mM}$ Tris- $\mathrm{HCl} \mathrm{pH} \mathrm{8,0,5}$ $\mathrm{mM} \mathrm{KCl}, 2,5 \mathrm{mM} \mathrm{MgCl}_{2}, 0,2 \mathrm{mM}$ de cada nucleotídeo, $20 \mathrm{rmol}$ de cada primer e 0,5 unidades de Taq DNA Polimerase (Cenbiot, Porto Alegre, Brasil). A amplificação foi executada em um termociclador GeneAmp PCR System 2400 (Perkin Elmer Instruments, USA). A reação 
foi realizada com um ciclo de desnaturação inicial $\left(94^{\circ} \mathrm{C}, 5 \mathrm{~min}\right)$, seguido por 25 ciclos de desnaturação $\left(94^{\circ} \mathrm{C}, 1 \mathrm{~min}\right)$, anelamento $\left(64^{\circ} \mathrm{C}, 1 \mathrm{~min}\right)$ e extensão $\left(72^{\circ} \mathrm{C}, 1 \mathrm{~min}\right)$. Após, foi realizado um ciclo de extensão final $\left(72^{\circ} \mathrm{C}, 7 \mathrm{~min}\right)$.

Para a "nested-PCR", foram utilizados 30 ciclos com temperatura de anelamento de $54^{\circ} \mathrm{C}$ por $1 \mathrm{~min}$. As demais condições foram iguais às da PCR inicial.

A eletroforese dos produtos amplificados foi realizada em gel de agarose $1,2 \%$ corado com $0,5 \mu \mathrm{g} / \mathrm{mL}$ de brometo de etídio.

Sensibilidade e especificidade das reações de amplificação

A sensibilidade da "nested-PCR" foi determinada através de diluições seriadas (de base 10) da vacina Nobilis CAV P4. Este procedimento foi repetido cinco vezes de forma independente. A especificidade foi determinada usando 15 soros de reprodutoras avós negativas para CAV e 30 diferentes amostras de vírus e bactérias causadoras de doenças em aves dos seguintes agentes: 1 cepa do vírus da laringotraqueite (Beltrão et al. 2004), 5 cepas do vírus da bronquite infecciosa, 4 cepas do vírus da doença infecciosa da bolsa, 6 cepas do vírus da doença de Newcastle, 1 cepa de pneumovírus e 1 do vírus da bouba aviária (obtidos de vacinas comerciais); e 12 amostras de bactérias sendo uma amostra de cada de Ornithobacterium rhinotracheale (Canal et al. 2003), Pasteurella multocida, Haemophilus sp, Mycoplasma gallisepticum, Mycoplasma synoviae, Salmonella enteritidis, Salmonella gallinarum, Salmonella pullorum, Salmonella typhimurim, Reimerella anatipestipher, Bordetella bronchiseptica e Escherichia coli. Estas bactérias foram isoladas e cedidas gentilmente pelo Centro de Diagnóstico e Pesquisa em Patologia Aviária da UFRGS (CDPA).

Utilizaram-se, em cada amplificação, um controle positivo (vacina CAV P4), um controle negativo (soro de reprodutoras avós negativas para CAV), e um contendo todos os reagentes da amplificação, exceto o DNA molde.

\section{Seqüenciamento}

Os produtos de amplificação da "nested-PCR" dos animais inoculados experimentalmente foram seqüenciados, bem como os amplicons obtidos da PCR com a amostra vacinal utilizada na inoculação experimental. Os produtos de amplificação foram purificados com GFX ${ }^{\mathrm{TM}}$ PCR DNA and Gel Band Purification Kit (Amersham Biosciences, Suécia). Ambas as fitas foram seqüenciadas usando $30 \mathrm{ng}$ do produto da "nested-PCR", 2,8 pmol de cada primer, utilizando o Kit BigDye Terminator v3.1 Cycle Sequencing RR-100 (Applied Biosystems, USA), conforme instruções do fabricante. O seqüenciamento do DNA foi realizado em um seqüenciador automático ABI-PRISM 3100 Genetic Analyzer (Applied Biosystems, USA). Os resultados do sequienciamento foram verificados com a ajuda do programa Chromas, versão 1.45 (McCarthy 1996-1998). As sequiências foram alinhadas com as seqüências de CAV depositadas no GenBank com o auxílio do programa Clustal X (Thompson et al. 1997).

\section{RESULTADOS}

Quatro métodos de extração de DNA foram testados, buscando comparar a capacidade destes em obter DNA de CAV capaz de ser amplificado através da "nested-PCR". Todos os métodos testados foram capazes de gerar o produto de amplificação esperado. Contudo, o DNA extraído pelo protocolo descrito por Hirt (1967) gerou algumas bandas inespecíficas na "nested PCR". Os protocolos fenol/clorofórmio e CTAB/NaCl (Sambrook \& Russell 2001) geraram um produto de amplificação nítido, porém, com intensidade menor do que o produzido pelo protocolo que utiliza tiocianato de guanidina adaptado de Rademaker \& Bruijn (1997). Este último foi selecionado para os ensaios posteriores.

Não foi possível visualizar produtos de amplificação na primeira amplificação (PCR) após a eletroforese em gel de agarose (resultados não mostrados). A "nested-PCR" realizada com as amostras clínicas dos animais do Grupo B (vacinados) gerou um produto de amplificação com tamanho aproximado de 520 pb (Fig.1) em todas as coletas e em todos os órgãos testados. Entretanto, o mesmo produto de amplificação foi observado em algumas amostras dos animais do Grupo A (controle negativo).

A especificidade do teste foi confirmada com o seqüienciamento dos produtos de amplificação dos dois grupos de animais inoculados experimentalmente. As seqüências obtidas indicaram que os dois grupos de animais foram infectados com uma cepa de CAV idêntica à vacinal, utilizada na inoculação do Grupo B.

A sensibilidade da "nested-PCR", determinada a partir de diluições seriadas da vacina para CAV, foi de $0,16 \mathrm{TCID}_{50 \%}$. Não foram gerados produtos de amplificação a partir do DNA extraído de 15 soros de lotes de reprodutoras avós controlados para CAV e das 30 amostras de vírus e bactérias utilizadas para avaliar a especificidade da reação.

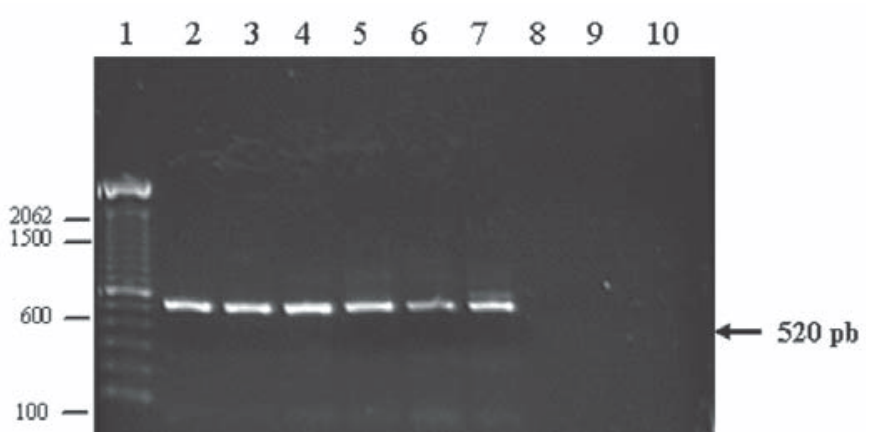

Fig.1. Eletroforese dos produtos da "nested-PCR" em gel de agarose $(1,2 \%)$ corado com brometo de etídio. Coluna 1 , marcador de tamanho molecular de $100 \mathrm{pb}$; coluna 2 , controle positivo da "nested-PCR"; colunas 3 a 7, amostras positivas; colunas 8 , 9 e 10 , controles negativos da extração de DNA, PCR e "nested-PCR", respectivamente.

Quadro 1. Resultados das reações de "nested-PCR" obtidos com as amostras procedentes de diferentes lotes sem (SD) ou com doença clinicamente aparente (CD)

\begin{tabular}{lccc}
\hline \multicolumn{1}{c}{ Tipo de amostra } & $\begin{array}{c}\text { Número de } \\
\text { amostras }\end{array}$ & $\begin{array}{c}\text { Número } \\
\text { de lotes }\end{array}$ & $\begin{array}{c}\text { Amostras } \\
\text { positivas }\end{array}$ \\
\hline Cama aviária15 & 15 & 15 & \\
Soro de frangos de corte & 20 & 3 & 20 \\
Soro de matrizes com anticorpos & 20 & 4 & 7 \\
Soro de avós negativas para CAV & 15 & 2 & 0 \\
Órgãos de frangos de corte SD & 30 & 15 & 26 \\
Órgãos de frangos de corte CD & 10 & 8 & 10 \\
Total & 110 & 47 & 78
\end{tabular}


O DNA do CAV foi detectado na maioria das amostras testadas no presente trabalho. As amostras positivas eram de aves pertencentes a 40 dos 47 diferentes lotes testados (Quadro 1). Todas as empresas investigadas tiveram pelo menos um lote positivo para o CAV.

\section{DISCUSSÃO E CONCLUSÕES}

Estudos anteriores utilizando testes de ELISA para a detecção de anticorpos em matrizes evidenciaram uma elevada prevalência de CAV nas empresas avícolas do Brasil (Brentano et al. 2000, Canal et al. 2004). No presente trabalho, buscamos confirmar a presença do CAV através da detecção do DNA deste agente, inicialmente em pintos infectados experimentalmente e, subseqüentemente, em amostras de galinhas de criações comerciais e em amostras de cama utilizadas nestas criações. A primeira etapa consistiu em verificar qual protocolo de purificação de DNA seria o mais adequado para a extração de DNA viral a partir de diversos tipos de amostras de tecidos de aves. Constatou-se que o DNA purificado por tiocianato de guanidina adaptado de Rademaker \& Bruijn (1997) gerou uma maior quantidade de produtos de amplificação na "nested-PCR" sem o aparecimento de bandas espúrias, razões pelas quais o mesmo foi adotado para a continuação deste estudo. Além disso, este protocolo mostrouse mais rápido e econômico do que os demais testados. Estas características são importantes na implementação de uma técnica adaptável à rotina diagnóstica do laboratório.

O protocolo utilizado permitiu a extração de DNA viral adequado para as reações de amplificação, a partir de tecidos, soro e amostras de cama aviária. Este foi o primeiro trabalho que descreveu a detecção do DNA do CAV a partir de cama aviária. $\mathrm{O}$ CAV é resistente no meio ambiente (Schat 2003), além de ser excretado nas fezes em grandes quantidades (Hoop 1992). Desta maneira, a utilização de cama aviária para a detecção do vírus possui algumas vantagens, já que não requer o sacrifício e nem necropsias de animais, além de permitir a amostragem de vários animais de um mesmo lote. A deteç̧ão do DNA do CAV a partir de cultivos celulares, como proposto previamente (Todd et al. 1992, Imai et al. 1998), é pouco prática na rotina diagnóstica, uma vez que são necessários dias para a multiplicação do vírus, o que torna o diagnóstico mais demorado e oneroso. Além disso, algumas amostras não replicam em cultivos celulares (Islam et al. 2002), podendo gerar resultados falsos negativos.

Considerando que as amostras de CAV circulantes no Brasil poderiam apresentar diferenças genéticas em relação às que apresentam sequiências disponíveis no Genbank, buscou-se estabelecer uma reação que diminuísse os riscos de obtenção de resultados falsos negativos e ao mesmo tempo proporcionando uma alta especificidade e sensibilidade. Nesse sentido, selecionaram-se primers de seqüiências conservadas do gene que codifica a VP1. Associando uma extração de DNA eficiente e condições ideais de amplificação, foi possível desenvolver uma "nestedPCR" com sensibilidade equivalente à detecção de 0,16 DICC $_{50}$ em cultivos celulares Outros protocolos descritos foram capazes de detectar aproximadamente 100 cópias do genoma (Tham 7 Stanislawek 1992), ou 100 a 200 moléculas de DNA (Cardona et al. 2000), ou $10^{0,5}$ DICC $_{50}$ (Imai et al. 1998). Davidson et al.
(2004) utilizando um protocolo descrito por Imai et al. (1998), não foram capazes de detectar o DNA viral em lotes sem sinais clínicos, provavelmente, devido à sensibilidade do teste. A "nestedPCR" aqui descrita foi aproximadamente 20 vezes mais sensível do que esta última (Imai et al. 1998), sendo capaz de amplificar o DNA do CAV mesmo em lotes com infecção subclínica. Este tipo de infecção causa imunodepressão (Adair 2000, Schat 2003), potencializa infecções causadas por patógenos oportunistas (Could et al.1992a,b, Miles et al. 2001, Davidson et al. 2004) e provoca diminuição da eficiência de vacinas (Schat 2003). Desta forma, o diagnóstico de formas subclínicas da infecção em lotes com baixo desempenho é importante para identificar as causas de perdas econômicas, já que os sinais observados podem ser causados por outros agentes oportunistas.

Os resultados obtidos com os soros de frangos de corte sem anticorpos para o CAV (Rubin et al. 2003) e positivos na "nestedPCR" sugerem que frangos sem anticorpos para o CAV, mas com infecção recente, estão presentes no momento do abate. Isso revela que a utilização de testes de diagnóstico baseados na detecção de anticorpos pode ser pouco informativa no monitoramento das infecções causadas por este vírus.

A alta sensibilidade da "nested-PCR" também é uma característica importante nas investigações que visam determinar a transmissão vertical do vírus ou a provável latência do mesmo (Todd et al. 1992, Miller et al. 2003). Ao realizar a "nested-PCR" com soro de matrizes com anticorpos para CAV, constatou-se que o DNA do agente pode persistir mesmo depois de ocorrida a soroconversão, como igualmente observado por outros autores (Cardona et al. 2000). Nesse sentido, os resultados aqui obtidos subsidiam os achados de Miller et al. (2003), Sommer \& Cardona (2003) e Brentano et al. (2005) que demonstraram que matrizes com anticorpos podem transmitir o vírus para a progênie. A transmissão vertical é a mais preocupante, já que os sinais clínicos são mais acentuados quando a infecção acontece nos primeiros dias de vida (Schat 2003). A detecção do DNA de CAV a partir de soro poderá ser usada como ferramenta para futuros estudos sobre transmissão vertical e persistência do vírus após a soroconversão.

A contaminação dos animais controle utilizados na infecção experimental, provavelmente, ocorreu devido à contaminação cruzada durante o experimento. Os resultados do seqüenciamento reforçam essa hipótese, visto que os animais deste grupo apresentaram um produto de amplificação com seqüência idêntica a da amostra vacinal. Estes achados reforçam a alta capacidade de disseminação deste vírus e a necessidade da utilização de medidas de biossegurança rigorosas para evitar a disseminação deste vírus entre os plantéis (Schat 2003).

Os resultados obtidos no presente trabalho permitem concluir que a "nested-PCR" estabelecida para o CAV foi específica e sensível, possibilitando a detecção do agente em infecções clínicas e subclínicas, em aves com e sem anticorpos e na cama empregada em sua criação. Constatou-se que o vírus está presente na maioria das empresas avícolas da Região Sul do Brasil investigadas.

Agradecimentos.- Agradecemos às empresas avícolas pelo fornecimento das amostras biológicas. S. Simionatto e L.L. Rubinreceberam bolsa de estudos da Coordenação de Aperfeiçoamento de Pessoal de Nível Superior 
(CAPES). Ao Conselho Nacional de Pesquisa (CNPq), à Pró-reitoria de Pesquisa da UFRGS e à Fundação de Amparo a Pesquisa do Estado do Rio Grande do Sul (FAPERGS) pelo suporte financeiro.

\section{REFERÊNCIAS}

Adair B.M. 2000. Immunopathogenesis of chicken anemia virus infection. Develop. Comp. Immunol. 24:247-255.

Beltrão N., Furian T.Q., Leão J.A., Pereira R.A., Moraes L.B. \& Canal C.W. 2004. Detecção do vírus da laringotraqueite das galinhas no Brasil. Pesq. Vet. Bras. 24(2):85-88.

Brentano L., Silva B.G., Sayd S. \& Flores S.W. 2000. Anticorpos para o vírus da anemia das aves (CAV) em matrizes de corte do Brasil. Revta Bras. Ciênc. Avícola 2(2):157-179.

Brentano L., Lazzarin S., Bassi S.S., Klein T.A.P., Schat K.A. 2005. Detection of chicken anemia virus in the gonads and in the progeny of broiler breeder hens with high neutralizing antibody titers. Vet. Microbiol. 105:65-72.

Canal C.W., Rocha S.L.S., Leão J.A., Fallavena L.C.B., Oliveira S.D. \& Beltrão N. 2003. Detecção de Ornithobacterium rhinotracheale (ORT) por meio da reação em cadeia da polimerase (PCR). Ciência Rural, Santa Maria, 33:377379.

Canal C.W., Ferreira D.J., Macagnan M., Fallavena L.C.B, Moraes H.L.S. \& Wald V.A.B. 2004. Prevalence of antibodies against chicken anemia virus in broiler breeders in southern Brazil. Pesq. Vet. Bras. 24(2):89-92.

Cardona C.J., Oswald W.B. \& Schat K.A. 2000. Distribution of chicken anaemia virus in the reproductive tissues of specific-pathogen-free chickens. J. Gen. Virol. 81:2067-2075.

Chettle N.J., Eddy R.K., Wyeth P.J. \& Lister S.A. 1989. An outbreak of disease due to chicken anaemia agent in broiler chickens in England. Vet. Rec. 124:211-215.

Davidson I., Kedem M., Borochovitz H., Kass N., Ayali G., Hamzani E., Perelman B., Smith B. \& Perk S. 2004. Chicken anemia virus infection in Israeli commercial flocks: virus amplification, clinical signs, performance, and antibody status. Avian Dis. 48:108-118.

Hirt B. 1967. Selective extraction of polyoma DNA from infected mouse cell cultures. J. Mol. Biol. 26:365-369.

Hoop R.K. 1992. Persistence and vertical transmission of chicken anemia agent in experimentally infected laying hens. Avian Pathol. 21:493-501.

Imai K., Mase M., Yamaguchi S. \& Yuasa N. 1998. Detection of chicken anaemia virus from formalin-fixed tissues by polimerase chain reaction. Res. Vet. Sci. 64:205-208.

Islam M.R., Johne R., Raue R., Todd D. \& Müller H. 2002. Sequence analysis of the full-lenght cloned DNA of chicken anemia virus (CAV) strain from Bangladesh: evidence for genetic grouping of CAV strain based on the deduced amino acid sequence. J. Vet. Med. B 49:332-337.

McCarthy C. 1996-1998. Chromas. Versão 1.45 (32-bit). School of Health Science, Griffith University, Australia. http:/technelysium.com.au/ chromas.html

McNulty M.S., Mcilroy S.G., Bruce D.W. \& Todd D. 1991. Economic effects of subclinical chicken anemia agent infection in broiler chickens. Avian Dis. 35:263-268.

Miles A.M., Reddy S.M. \& Morgan R.W. 2001. Coinfection of specific- pathogen-free chickens with Marek's disease virus (MDV) and chicken infectious anemia virus: effect of MDV pathotype. Avian Dis. 45:9-18.

Miller M.M., Ealey K.A., Oswald W.B. \& Schat K.A. 2003. Detection of chiken anemia virus DNA in embrional tissues and eggshell membranes. Avian Dis. 47:662-671.

Murphy F.A. 1996. Virus taxonomy, p.15-58. In: Fields B.N., Knipe D.M. \& Howley, P.M. (ed.) Fields Virology. 3rd ed. Lippincott-Raven, Philadelphia.

Noteborn M.H.M., De Boer G.F., Van Roozelaar D.J., Karreman C., Kranenburg O., Vos J.G., Jeurissen S.H.M., Hoeben R.C., Zantema A., Koch G., Van Ormondt G.H. \& Van Der Eb A.J. 1991. Characterization of cloned chicken anemia virus DNA that contains all elements for the infectious replication cycle. J. Virol. 65(6):3131-3139.

Pringle C.R. 1999. Virus Taxonomy at the XIth International Congress of Virology, Sydney, Australia. Arch. Virol. 144:2065-2070.

Rademaker J.L.W. \& De Bruijn F.J. 1997. Characterization and classification of microbes by REP-PCR genomic fingerprinting and computer-assisted pattern analysis, p.151-171. In: Caetano-Anollés G. \& Gresshoff P.M. (ed.) DNA Markers: Protocols, Applications, and Overviews. J. Wiley and Sons, New York.

Renshaw R.W., Soiné C., Weinkle T., O'Connel P.H., Ohashi K., Watson S., Lucio B., Harrington S. \& Schat K.A. 1996. A hypervariable region in vp1 of chicken infectious anemia virus mediates rate of spread and cell tropism in tissue culture. J. Virol. 70:8872-8878.

Rubin L.L., Ávila A.L., Ribeiro, A.M.L., Wald V.B. \& Canal C.W. 2003. Comparação do desempenho entre frangos de corte positivos e negativos para anticorpos contra o vírus da anemia das galinhas. Braz. J. Microbiol. 34:88-89.

Sambrook J. \& Russel D.W. 2001. Molecular Cloning. A Laboratory Manual. 3rd ed. Cold Spring Harbor Laboratory Press, New York.

Schat K.A. 2003. Infectious anemia, p.182-202. In: Saif Y.M., Barnes H.J, Fadly A.M., Clisson J.R., McDougald L.R. \& Swayne D.E. (ed.) Diseases of Poultry. 11th ed. Iowa State University, Ames. 1189p.

Sommer F. \& Cardona C. 2003. Chicken anemia virus in broilers: dynamics of the infection in two commercial broiler flocks. Avian Dis. 47:14661473.

Tham K.M. \& Stanislawek W.L. 1992. Polimerase chain reaction amplification for direct detection of chicken anemia virus DNA in tissues and sera. Avian Dis. 36:1000-1006.

Thompson J.D., Gibson T.J., Plewniak F., Jeanmougin F. \& Higgins D.G. 1997. The ClustalX windows interface: flexible strategies for multiple sequence alignment aided by quality analysis tools. Nucleic Acids Res. 24:4876-4882.

Todd D., Mawhinney K.A. \& McNulty M.S. 1992. Detection and differentiation of chicken anemia virus isolates by using the polimerase chain reaction. J. Clin. Microbiol. 30:1661-1666.

Yilmaz H., Turan N., Ozgur N.Y., Helps C.R. \& Akay O. 2001 Detection of chicken anemia virus DNA in the thymus of naturally infected chicks in Turkey. Avian Dis. 45:529-533.

Yuasa N., Noguchi K., Furata K. \& Yoshida I. 1980. Maternal antibody and its effect on the susceptibility of chicks to chickenanemia agent. Avian Dis. 24:197-201.

Yuasa N., Taniguchi T. \& Yoshida I. 1979. Isolation and some characteristics of an agent inducing anemia in chicks. Avian Dis. 23:366-385. 